\title{
Surveillance for Hepatocellular Carcinoma
}

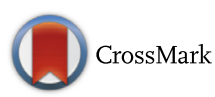

\author{
Jeyamani Ramachandran* \\ Department of Hepatology, Christian Medical College, Vellore, Tamil Nadu, India
}

\begin{abstract}
Hepatocellular carcinoma (HCC) is a dreaded complication of cirrhosis as it is the commonest cause of mortality in these patients.The last few years have seen a dramatic improvement in the management of this tumor as nearly $50-70 \%$ of selected patients with early HCC survive for a median period of up to 5 years after liver transplantation, resection or local ablation. Surveillance has been found to be an effective tool to detect early tumors and expand the applicability of these curative treatment options. Semiannual ultrasonogram is recommended for surveillance by the American, European and Asia Pacific liver societies and is the standard of care in many countries. There is increasing evidence that this practice improves survival too. Since the only way to improve the outlook of HCC is its diagnosis prior to commencement of symptoms, providing surveillance becomes a major responsibility of physicians caring for patients with chronic liver disease. This review attempts to discuss the population at risk of HCC, modalities and frequency of surveillance tests, cost effectiveness and also the logistics of its delivery in the Indian context. (J CuIn Exp Hepatol 2014;4:S50-S56)
\end{abstract}

$\mathrm{H}$ epatocellular carcinoma (HCC) is a dreaded complication of cirrhosis as it is the commonest cause of mortality in these patients. ${ }^{1}$ The last few years have seen a dramatic improvement in the management of HCC. Around 50-70\% of selected patients with early HCC survive for a median period of up to 5 years after liver transplantation, resection or local ablation. ${ }^{2,3}$ Surveillance has been able to detect early tumors and expand the applicability of curative treatment options. Semiannual ultrasonogram is recommended by the American, European and Asia Pacific liver societies and is the norm in many developed countries. There is increasing evidence that this practice improves survival too. ${ }^{4,5}$ The importance of surveillance is reiterated by a recent study from India which found more than 50\% patients diagnosed to have HCC between the years 2005 2010 in TNM stage $4 .{ }^{6}$ Since, curative treatment options are precluded by an advanced tumor stage and liver disease it becomes very essential that HCCs are detected at an early stage which can be only achieved by a meticulous surveillance program.

Surveillance can be defined as constant vigilance of a subject at risk of developing a disease by performing a test or a combination of the tests periodically. Hepatocellular carcinoma (HCC) has definite risk factors and predis-

Keywords: surveillance, hepatocellular carcinoma, cirrhosis Received: 11.8.2013; Accepted: 3.3.2014; Available online 21.4.2014 Address for correspondence: Jeyamani Ramachandran, Professor, Department of Hepatology, Christian Medical College, Vellore, Tamil Nadu, India.

E-mail: jeyapati@yahoo.com

Abbreviations: HCC: hepatocellular carcinoma; MRI: magnetic resonance imaging; NAFLD: non-alcoholic fatty liver disease; RCTs: randomized controlled trials; USG: ultrasonogram

http://dx.doi.org/10.1016/j.jceh.2014.03.050 posing conditions enabling surveillance modalities to be easily applied. In addition, the tests employed for surveillance are non invasive and curative treatment is available when the tumor is detected at an early stage. But the crucial questions to be answered are whether surveillance prolongs survival and if it is cost effective.

\section{EFFICACY OF SURVEILLANCE}

Ideally, reduction of disease specific mortality should be the aim of any surveillance program. Though in the case of HCC, surveillance is shown to achieve stage migration or detection of disease at earlier stage $e^{7,8}$ by itself this is not a robust endpoint compared to survival.

There are only two available randomized controlled trials (RCTs) comparing surveillance to none, both from China in chronic hepatitis B patients. Zhang and Yang randomized a large proportion of HBsAg positive patients (with and without cirrhosis) and those with history of chronic hepatitis to surveillance using USG and AFP and no screening. ${ }^{9}$ They reported that surveillance decreased HCC related mortality by $37 \%$ despite poor adherence. Another study was population based and randomized hepatitis B carriers to screening with AFP 6 monthly. With AFP cut off $20 \mathrm{ng} / \mathrm{mL}$, they found more early stage cancers in the screened group but the difference did not translate into long-term survival benefit. ${ }^{10}$ This was probably because of under utilization of curative therapies in patients with detected tumors.

Nevertheless, many clinic based retrospective cohort studies in cirrhotics have found significantly better survival in those whose tumors were asymptomatic but detected on surveillance. ${ }^{7,8,11-14}$ These studies are not free from lead time bias (better survival due to anticipated diagnosis of HCC) and length bias (surveillance picking up slow growing tumors) since they are uncontrolled. But when 
corrected for lead time bias, there was still significant improvement in survival. ${ }^{15}$

HCCs detected when symptomatic are associated with a poor prognosis and ones detected on surveillance fare as well as incidentally found ones. ${ }^{16}$ Moreover, many studies also showed a favorable tumor stage detected on surveillance. ${ }^{7,8,12}$ In fact, the risk of finding an advanced HCC is reduced by $70 \%$ in patients who are on surveillance. ${ }^{14}$ Since surveillance increases the applicability of curative options with almost 50\% 5-year survival rates, it actually decreases disease related mortality. A randomized controlled trial may be considered unethical in this scenario. Hence the balance is tilted in favor of surveillance for the benefit of diagnosis of early HCC.

\section{COST EFFECTIVENESS}

Though there is no experimental data to decide on the exact level of HCC incidence to initiate surveillance, there are several decision analysis and cost effectiveness models guiding the decision as to when to enter cirrhotics into HCC surveillance. These models have some inherent differences in the interventions but they all agree that surveillance is cost effective. Coon et al, attempted a systematic review of surveillance for HCC in cirrhotics and failed to find any study that fulfilled the standard criteria and created a computerized decision analytic model comparing various surveillance strategies. ${ }^{17}$ They concluded that semi annual surveillance tripled the number of operable cases and halved deaths due to HCC compared to no surveillance. Different authors have found different levels of HCC incidence $>1.5 \%$ per year ${ }^{18} 1.4 \%$ year $^{19}$ any level ${ }^{20}$ to be cost effective with AFP and USG. AASLD and EASL recommend surveillance for patients with cirrhosis of varying etiologies, to be offered when the risk of HCC is $1.5 \%$ per year or greater. Cost effectiveness of HCC depends upon the receipt of potentially curative therapy. If treatment is not available, not given or patient is ineligible to receive due to liver disease severity or other medical conditions, then HCC surveillance cannot be considered cost effective.

A good surveillance program should define clearly the population at risk, the modalities of testing and recall policies to deal with abnormal tests encountered.

\section{WHO IS AT RISK OF HEPATOCELLULAR CARCINOMA}

HCC is a well-known complication of cirrhosis. $60-97 \%$ of HCCs occur in the background of cirrhosis ${ }^{21-23}$ though it can occur in its absence as well. Incidence of HCC among cirrhotics in India was found to be 1.6\% among 100 person years. ${ }^{24}$ Published data on the 5year cumulative incidence of HCC in cirrhotics varies from $17 \%$ in the west to $30 \%$ in Japan for HCV; $21 \%$ for hereditary hemochromatosis; $10 \%$ for $\mathrm{HBV}$ in the west and $15 \%$ in endemic regions, alcoholic cirrhosis $8 \%$ and biliary cirrhosis $4 \%$ HBV/HCV and HBV/HDV co infections increase the HCC risk (2- to 6-fold relative to each infection alone) as does alcohol abuse (2- to 4fold relative to alcohol abstinence. ${ }^{1}$

A large case series of HCC from India reveals HBV to be the commonest cause in upto $50 \%, \mathrm{HCV}$ in $10-12 \%$ and $20 \%$ to be cryptogenic cirrhosis. ${ }^{23} \mathrm{~A}$ recent study from India which looked at risk factors for HCC including viral PCRs on 374 patients by Kar et al revealed HBV as a major cause in $63 \% \mathrm{HBV}, \mathrm{HCV}$ in $27 \%{ }^{25}$ Aflatoxin exposure was present in $17 \%$ of HCC cases. Data from a European cohort EUROHEP prospective study group, mentions the probability of $\mathrm{HCC}$ appearing 5 years after diagnosis of HBV cirrhosis to be $6 \%{ }^{26}$

Non-alcoholic fatty liver disease (NAFLD) related cirrhosis is considered as a major cause of the so called cryptogenic cirrhosis and increased risk of $\mathrm{HCC}$ is reported by many investigators as cohort, case-control and population-based studies and confirmed in a meta analysis in these patients. ${ }^{27,28}$ A systematic review of the association between NAFLD and risk for HCC done taking into consideration 17 cohort studies (population based, clinic based, natural history) 18 case control studies and 26 case series or case reports, concluded that risk of HCC was limited to NAFLD or NASH cases with cirrhosis. ${ }^{29}$ There is no evidence to support surveillance of general NAFLD or NASH cohort without cirrhosis for HCC.

\section{NON-CIRRHOTIC CHRONIC HEPATITIS PATIENTS}

The incidence of HCC in patients with non-viral chronic liver disease without cirrhosis, such as autoimmune liver disease, genetic hemochromatosis, a1-antitripsin deficiency, and Wilson disease is not common. Usually HCC occurs in these conditions only with cirrhosis. ${ }^{30}$

\section{CHRONIC HEPATITIS B}

In a prospective controlled study of 22,707 men in Taiwan, Beasley et al showed an incidence of $0.5 \%$ HCC in HBV carriers. Chronic hepatitis $\mathrm{B}$ virus carriers have a 100 -fold relative risk of developing HCC compared with non-carriers, which decreases if infection is acquired in adulthood. ${ }^{31} \mathrm{Ac}-$ cording to expert opinion, surveillance can be recommended if the annual incidence is more than $0.2 \%{ }^{4}$

Unlike the Europeans with CHB where HBV carriers do not develop HCC without cirrhosis, ${ }^{32,33}$ Asian HBV carriers are at risk of HCC irrespective of HBV replication status. $^{34-36}$ Study of inactive carriers (HBV DNA $<2000 \mathrm{IU} / \mathrm{ml}$, normal ALT, no cirrhosis) from the participants of REVEAL cohort revealed a substantial risk of HCC compared to HBsAg negative individuals especially among older individuals. ${ }^{37}$ Since the incidence 
of HCC starts to exceed $0.2 \%$ per year beyond the age of 40 , as it is recommended for other Asian men. ${ }^{4,5}$ Indian men should start surveillance as they cross 40 years. The incidence of HCC in women is lower than in men, although age-specific incidence rates are not reported. However, it is appropriate to start surveillance at about age 50 in Indian women. Surveillance is also recommended in HBV carriers if there is family history of HCC, the exact age at which it should be started is not clear. ${ }^{38}$ The linear relationship between HCC risk and DNA load has been shown in REVEAL study. ${ }^{39}$ In addition, E antigen positive status, DNA >100,00 IU/L, persistently elevated ALT and genotype $\mathrm{C}$ were found to have the highest risk scores for developing HCC. ${ }^{40}$

\section{CHRONIC HEPATITIS C}

In a large population study of 12,008 men from Taiwan, $\mathrm{HCV}$ antibody positive patients were 20 times more likely to have HCC, though the exact proportion of cirrhotics was not analyzed. ${ }^{41}$ Cumulative 5-year risk of HCC with only bridging fibrosis in HALT-C trial was $4.8 \%$, which is below the recommended $1.5 \%$ per year incidence to obtain survival benefit. ${ }^{42}$ But HCC was shown to occur even with bridging fibrosis in the absence of cirrhosis. But data from a case control study from India found low incidence of $\mathrm{HCC}$ in HCV carriers with no evidence of cirrhosis. ${ }^{36}$

A Japanese retrospective cohort study concluded that the risk of HCC in non-cirrhotics with HCV increased with the degree of liver fibrosis, from an annual incidence of $0.5 \%$ among patients with stage $\mathrm{F} 0$ or $\mathrm{F} 1$ fibrosis to $7.9 \%$ among patients with stage F4 fibrosis. The risk was higher in untreated patients with F2 and F3 fibrosis ${ }^{43}$ EASL suggests offering surveillance to $\mathrm{HCV}$ patients with bridging fibrosis whereas AASLD includes in the category of uncertain benefit. ${ }^{4,5}$ Since there is a small but definite risk of HCC in advanced fibrosis, we recommend that they be screened for HCC especially if untreated. Transient elastography could be useful to stratify risk of HCC among patients with Chronic HCV. ${ }^{44}$

\section{TREATED VIRAL HEPATITIS}

Successfully treated cases of chronic hepatitis B and C are at a low risk of HCC but not totally free from risk of HCC. ${ }^{45-47}$ Those with advanced fibrosis, cirrhosis or with other risk factors such as family history need to be under surveillance. $^{4,5}$

\section{WILL ALL CIRRHOTICS BENEFIT FROM SURVEILLANCE?}

Since the underlying cirrhosis related survival is a critical factor in determining the benefit obtained by surveillance, ${ }^{18}$ it should be offered to those patients who would be treated if HCC is diagnosed, which includes child's A and B class and excludes child's $C$ patients if they are not listed for LT. Survival benefit with surveillance has been shown in cirrhotics in child's A and B class unlike the situation in child's C. ${ }^{13}$ It should be limited to those on LT waiting list for child's $\mathrm{C}$ patients. Patients in Liver Transplantation waiting list also should be screened as the diagnosis of a new tumor gives priority and also to avoid subjecting disseminated HCC for liver transplantation. ${ }^{4}$

Though it is implicit that advanced age and co morbidities may argue against inclusion in a surveillance program due to questionable applicability of surgical options, there is no conclusive data to make any recommendation regarding age limit for surveillance. In fact retrospective cohort studies extend survival benefits to elderly patients also.?

\section{SURVEILLANCE STRATEGY}

Two modalities widely used for surveillance are radiological and serological.

Many professional societies such as the AASLD, EASL and APASL recommend 6 monthly abdominal Ultrasonogram (USG) as the preferred test for HCC surveillance. ${ }^{4,5,48}$

\section{ULTRASONOGRAPHY}

This is the most commonly used surveillance test which scores over any other radiological test in view of its noninvasive nature and lack of radiation.

Though it has been found to be very sensitive in detecting asymptomatic tumors (94\%), the sensitivity for detecting early stage tumors is lower (63\%) as shown in a recent meta analysis. ${ }^{49}$ But it is currently the best surveillance tool for early-stage HCC among patients with cirrhosis. Performing ultrasound every 6 months instead of annually significantly improves sensitivity for detection of early HCC to $70 \%{ }^{49}$ However, the performance of USG as a surveillance test depends on the experience of the examiner especially in cirrhotics with nodules.

When carefully done by experts, as shown in a retrospective analysis of a clinic based surveillance program, with surveillance interval varying from 2 to 8 months, only $1.4 \%$ of tumors exceeded $3 \mathrm{~cm} .{ }^{50}$ Triple phase CT (computerized tomogram) or MRI (magnetic resonance imaging) cannot be advocated for routine surveillance due to high cost and radiation exposure. But when a patient is listed for liver transplantation, or in the presence of obesity, ascites and very coarse liver, all of which preclude a good sonological window, CT or MR can be used to investigate for the presence of HCC. When used in combination (AFP and USG), the costs and false positive rates went up with minimal gain in HCC detection in an urban HBV positive community of China. ${ }^{51}$ Thus, USG is the recommended surveillance modality for HCC. Since cirrhotic coarse livers may make detection of small lesions difficult, AASLD recommends special training for radiologists performing surveillance. ${ }^{4}$ 


\section{Surveillance Interval}

A recent meta analysis done with an aim to determine the performance characteristics of USG for the detection of HCC in cirrhotics showed that six monthly USGs detected significantly more early cancers than annual USGs. ${ }^{49}$

A multi center randomized trial from Europe, compared surveillance with 3 months and 6 months USG. Although a significantly higher percentage of lesions were $<10 \mathrm{~mm}$ in size in the 3-monthgroup (5-year cumulative incidence $41 \%$ vs $28 \% ; P<0.002$ ), there was no difference in the cumulative incidence of HCC, or prevalence of lesions $>30 \mathrm{~mm}$ in diameter between the study groups $(7.8 \%$ vs $9.1 \%$, respectively; $P=0.48)$. Similar proportion of tumors was within Milan criteria and received curative therapy. The 3 -month surveillance group had a significantly higher incidence of focal, nonmalignant lesions, thereby leading to an increased number of unnecessary recall procedures. ${ }^{52}$

A recent report from an $\mathrm{HBV}$ endemic area (Korea), where characteristics of cancer and 5-year survival in patients diagnosed as HCC during a 15-year prospective follow-up were compared between surveillance interval of $<6$ months and beyond 6 months showed that shorter surveillance interval detected significantly smaller tumors with better 5 year survival even after correcting for lead time bias. ${ }^{53}$

Based on tumor doubling time, USG screening 6 monthly is a reasonable strategy. ${ }^{54,55}$ A retrospective Italian cohort did not find any survival advantage in a semiannual as against annual USG $^{14}$ when they studied patients between 1988 and 1998. But the same group has concluded in a more recent multicentre study that semiannual screening is better than annual screening in terms of more early cancers and improved chances of treatment applicability $^{56}$ on following up their HCC cohort from 1988 to 2006.

\section{Recall Policy}

A successful surveillance program should have a clear recall policy to act upon abnormalities found on screening.

1. In a cirrhotic any nodule $<1 \mathrm{~cm}$, can be considered non malignant and kept on a close 4 monthly follow-up. ${ }^{57}$

2. In lesions between 1 and $2 \mathrm{~cm}$, if the imaging is indeterminate (typical diagnostic features are arterial enhancement and venous phase wash out), biopsy review by an experienced pathologist is required. If biopsy is inconclusive for malignancy, repeat imaging or close followup and or repeat biopsy is advised.

3. In lesions beyond $2 \mathrm{~cm}$, typical imaging findings on contrast study will confirm the diagnosis. If not biopsy is to be done to confirm diagnosis.

Once a suspicious nodule is diagnosed, patients should be referred to a higher center with better facilities. ${ }^{4}$

\section{SEROLOGICAL MARKERS}

Serum Alfa fetoprotein (AFP) is the most widely tested biomarker in HCC. But an obituary is written for the same and is no longer recommended as a screening test except by APASL. ${ }^{48}$ It does not perform well as a surveillance test because fluctuating levels may occur in any chronic $\mathrm{HBV}$ and $\mathrm{HCV}$, not necessarily due to HCC formation. ${ }^{58}$ If elevated, is helpful to define patients at risk for HCC. ${ }^{59}$ Cholangiocarcinoma, another common hepatobiliary tumor is also associated with elevated AFP. ${ }^{60}$

When used as a diagnostic test, as shown in a case control study which evaluated the sensitivity, specificity, positive and negative predictive value of AFP in 170 HCCs and similar number of CLDs, the sensitivity was poor (60\%) at a value of $20 \mathrm{ng} / \mathrm{mL}$ but the specificity was $84 \%$. ${ }^{61}$ When the cut off was increased to $200 \mathrm{ng} / \mathrm{mL}$, the sensitivity dropped to a dismal $22 \%$ and specificity soared up to $99 \%$. In addition, when the prevalence of HCC was low ( $<5 \%$ ) a cut off of $20 \mathrm{ng}$ had a very low PPV. This makes it unsuitable as a surveillance test in Chronic Hepatitis B with an incidence $<1 \%$. Results by Sherman et al in Canada also found that the sensitivity of periodic testing in $1069 \mathrm{HBV}$ carriers every six months to be $64 \%$ as in diagnosis and specificity of $91 \% .{ }^{62}$ The role of AFP alone as a screening test was assessed in 2 situations. A long-term population based study in Alaskan natives positive for HBsAg, found screening with AFP to be a useful test in detecting more tumors (95\% sensitivity and specificity) that could be resected and achieved long term survival compared to historical controls. ${ }^{63}$ This result was not replicated in any other study. A randomized study of screening chronic HBV carriers with AFP found no survival benefit of the program though more early stage tumors were found in the screened group. ${ }^{10}$ The follow-up was poor and the test sensitivity was only $56 \%$.

The lack of efficacy of AFP alone in HCC surveillance was evident when evaluated prospectively as a part of HALT C trial. AFP and or des-gammacarboxyprothrombin (DCP) at and 12 months prior to a diagnosis of HCC had low sensitivity especially at high cut offs. ${ }^{56}$ The authors concluded that biomarkers could complement USG in the detection of early HCC but none of them show optimal performance. ${ }^{64}$ Moreover, early tumors for which surveillance is advocated may not produce AFP elevations. ${ }^{61}$ AFP alone is not recommended as a surveillance test for these reasons. A recent meta analysis demonstrated that at any cut off, addition of AFP to USG does not provide any advantage in detecting early $\mathrm{HCCs}^{49}$ with only non significant increase in pooled sensitivity from $63 \%$ to $69 \%$. Thus, in a patient at risk of HCC, serum AFP is not an ideal surveillance test when performed alone. 
Other serological markers that are studied include DCP, glycosylated AFP-L3 fraction of total AFP, alpha fucosidase, glypican 3 (GPC-3), heat shock protein 70 (HSP70), and DR-70 immunoassay. None have been found to be of any use in surveillance.

\section{EFFECTIVE DELIVERY OF SURVEILLANCE AND MANAGEMENT OF SURVEILLANCE FAILURE}

Failures in surveillance process are often seen in clinical practice of many cancers. The reasons could be absence of screening, absence of follow-up for abnormal tests or absence of detection despite completing screening and follow-up. ${ }^{65}$ This was evaluated for HCC in a retrospective analysis of HALT-C data where even among patients closely followed by expert hepatologists in academic centers, nearly one-third of patients had inconsistent HCC surveillance. ${ }^{66}$ Surveillance failure was due to an absence of detection, in $70 \%$ of patients with tumors beyond Milan criteria in spite of doing both USG and AFP. There is strikingly poor utilization of surveillance even in high-risk groups. In a study of 13,002 HCV-infected US veterans diagnosed with cirrhosis during 1998-2005, only $12 \%$ received annual surveillance in the 3 years following their cirrhosis being diagnosed and less than $50 \%$ received a surveillance test in the first year following diagnosis. ${ }^{67}$ The data from Korea was similar with only $27 \%$ HBV cirrhotics being screened confirming the poor utilization of surveillance in clinical practice. ${ }^{68}$ By prospectively entering cirrhotics into a chronic disease management program, providing automatic reminders and involving nurse practitioners as surveillance providers, Aberra et al showed significantly improved rate of surveillance from 74 to $93 \%$ compared to a prior cohort. ${ }^{69}$ The treating hepatologist is responsible for the execution of surveillance plan. Involving a nurse educator and improving surveillance with pre scheduled USG 6 monthly, is recommended to avoid high-risk patients missing out the benefit of an early diagnosis of HCC.

\section{RECOMMENDATION FOR IMPROVING THE UTILIZATION OF SURVEILLANCE}

1 Surveillance USG done by radiologists or technicians with special training in tertiary medical centers

2 In medical centers caring for cirrhotics, surveillance can be provided as a part of a CLD management program coordinated by a nurse practitioner separate from the routine clinical care of cirrhotics

\section{ISSUES PERTAINING TO INDIA}

Review of literature and international guidelines leave no room for doubt regarding the utility of surveillance in improving the care of cirrhotics. The economics of surveillance when estimated as a part of a prospective study by Acharya et al using a surveillance protocol 6 monthly USG, AFP and triple phase CT abdomen found the cost to be exorbitant in India. ${ }^{70}$ As treatment of early cancers is the aim, while initiating HCC surveillance, patients should be counseled about the cost of potentially available curative treatment options in addition to the cost of surveillance tests. Surveillance USG should be performed at designated centers with trained radiologists. The increasing incidence of cirrhosis mandates an urgent need for establishing a surveillance program in major liver units across the country and periodic assessment of its utility, cost effectiveness and the interventions that stem from it.

\section{SUMMARY}

The available evidence in favor of surveillance is not statistically robust and systematic reviews report many limitations with the available studies. ${ }^{17,49}$ Though clearly the best, a randomized controlled trial of surveillance for liver cancer, with mortality from the disease as the endpoint may not be ethically acceptable. On the other hand, semi annual USG surveillance of cirrhotics and other high-risk groups improves the detection of tumors which have a high chance of cure and is readily accepted by hepatologists all over the world. Providing surveillance using specially trained personnel, delivery of the same using nurse practitioner based protocols and automatic reminders may further improve patient and physician compliance and enhance the benefit of surveillance.

\section{CONFLICTS OF INTEREST}

The author has none to declare.

\section{REFERENCES}

1. Fattovich G, Stroffolini T, Zagni I, Donato F. Hepatocellular carcinoma in cirrhosis: incidence and risk factors. Gastroenterology. 2004;127(5 suppl 1):S35-S50.

2. Llovet JM, Bruix J. Novel advancements in the management of hepatocellular carcinoma in 2008. J Hepatol. 2008;48(suppl 1): S20-S37.

3. Arii S, Yamaoka Y, Futagawa S, et al. Results of surgical and nonsurgical treatment for small-sized hepatocellular carcinomas: a retrospective and nationwide survey in Japan. The Liver Cancer Study Group of Japan. Hepatol Balt Md. 2000;32(6):1224-1229. http://dx.doi.org/10.1053/jhep.2000.20456.

4. Bruix J, Sherman M, American Association for the Study of Liver Diseases. Management of hepatocellular carcinoma: an update. Hepatol Balt Md. 2011;53(3):1020-1022. http://dx.doi.org/10. 1002/hep.24199

5. European Association for Study of Liver, European Organisation for Research and Treatment of Cancer. EASL-EORTC clinical practice guidelines: management of hepatocellular carcinoma. Eur J Cancer Oxf Engl. 2012;48(5):599-641. http://dx.doi.org/10.1016/j. ejca.2011.12.021. 
6. Pal S, Ramachandran J, Kurien RT, et al. Hepatocellular carcinoma continues to be diagnosed in the advanced stage: profile of hepatocellular carcinoma in a tertiary care hospital in South India. Trop Doct. 2013;43(1):25-26. http://dx.doi.org/10.1177/ 0049475512473600 .

7. Trevisani F, Cantarini MC, Labate AMM, et al. Surveillance for hepatocellular carcinoma in elderly Italian patients with cirrhosis: effects on cancer staging and patient survival. Am J Gastroenterol. 2004;99(8):1470-1476. http://dx.doi.org/10.1111/j.15720241.2004.30137.x.

8. Yuen MF, Cheng CC, Lauder IJ, Lam SK, Ooi CG, Lai CL. Early detection of hepatocellular carcinoma increases the chance of treatment: Hong Kong experience. Hepatol Balt Md. 2000;31(2):330335. http://dx.doi.org/10.1002/hep.510310211.

9. Zhang B-H, Yang B-H, Tang Z-Y. Randomized controlled trial of screening for hepatocellular carcinoma. J Cancer Res Clin Oncol. 2004;130(7):417-422. http://dx.doi.org/10.1007/s00432004-0552-0.

10. Chen J-G, Parkin DM, Chen Q-G, et al. Screening for liver cancer: results of a randomised controlled trial in Qidong, China. J Med Screen. 2003;10(4):204-209. http://dx.doi.org/10.1258/ 096914103771773320.

11. Wong LL, Limm WM, Severino R, Wong LM. Improved survival with screening for hepatocellular carcinoma. Liver Transpl Off Publ Am Assoc Study Liver Dis Int Liver Transpl Soc. 2000;6(3):320-325. http://dx.doi.org/10.1053/Iv.2000.4875.

12. Sangiovanni A, Del Ninno E, Fasani $P$, et al. Increased survival of cirrhotic patients with a hepatocellular carcinoma detected during surveillance. Gastroenterology. 2004;126(4):1005-1014.

13. Trevisani F, Santi V, Gramenzi A, et al. Surveillance for early diagnosis of hepatocellular carcinoma: is it effective in intermediate/ advanced cirrhosis? Am J Gastroenterol. 2007;102(11):24482457. http://dx.doi.org/10.1111/j.1572-0241.2007.01395.x. quiz 2458.

14. Trevisani F, De Notariis S, Rapaccini G, et al. Semiannual and annual surveillance of cirrhotic patients for hepatocellular carcinoma: effects on cancer stage and patient survival (Italian experience). Am J Gastroenterol. 2002;97(3):734-744. http://dx.doi. org/10.1111/j.1572-0241.2002.05557.x.

15. Wong GL-H, Wong VW-S, Tan G-M, et al. Surveillance programme for hepatocellular carcinoma improves the survival of patients with chronic viral hepatitis. Liver Int Off J Int Assoc Study Liver. 2008;28(1):79-87. http://dx.doi.org/10.1111/j.1478-3231. 2007.01576.x.

16. Llovet JM, Burroughs A, Bruix J. Hepatocellular carcinoma. Lancet. 2003;362(9399):1907-1917. http://dx.doi.org/10.1016/ S0140-6736(03)14964-1.

17. Thompson Coon J, Rogers G, Hewson P, etal. Surveillance of cirrhosis for hepatocellular carcinoma: systematic review and economic analysis. Health Technol Assess Winch Engl. 2007;11(34):1-206.

18. Sarasin FP, Giostra E, Hadengue A. Cost-effectiveness of screening for detection of small hepatocellular carcinoma in western patients with Child-Pugh class A cirrhosis. Am J Med. 1996;101(4):422-434. http://dx.doi.org/10.1016/S00029343(96)00197-0.

19. Arguedas MR, Chen VK, Eloubeidi MA, Fallon MB. Screening for hepatocellular carcinoma in patients with hepatitis $C$ cirrhosis: a costutility analysis. Am J Gastroenterol. 2003;98(3):679-690.

20. Lin OS, Keeffe EB, Sanders GD, Owens DK. Cost-effectiveness of screening for hepatocellular carcinoma in patients with cirrhosis due to chronic hepatitis C. Aliment Pharmacol Ther. 2004;19(11):1159-1172. http://dx.doi.org/10.1111/j.13652036.2004.01963.x.

21. Benvegnù L, Noventa F, Bernardinello E, Pontisso P, Gatta A, Alberti A. Evidence for an association between the aetiology of cirrhosis and pattern of hepatocellular carcinoma development. Gut. 2001;48(1):110-115.

22. Kumar R, Saraswat MK, Sharma BC, Sakhuja P, Sarin SK. Characteristics of hepatocellular carcinoma in India: a retrospective analysis of 191 cases. QJM Mon J Assoc Physicians. 2008;101(6):479-485. http://dx.doi.org/10.1093/qjmed/hcn033.

23. Paul SB, Chalamalasetty SB, Vishnubhatla S, et al. Clinical profile, etiology and therapeutic outcome in 324 hepatocellular carcinoma patients at a tertiary care center in India. Oncology. 2009;77(34):162-171. http://dx.doi.org/10.1159/000231886.

24. Paul SB, Sreenivas V, Gulati MS, et al. Incidence of hepatocellular carcinoma among Indian patients with cirrhosis of liver: an experience from a tertiary care center in northern India. Indian J Gastroenterol Off J Indian Soc Gastroenterol. 2007;26(6):274-278.

25. Asim M, Sarma MP, Kar P. Etiological and molecular profile of hepatocellular cancer from India. Int J Cancer J Int Cancer. 2013;133(2):437-445. http://dx.doi.org/10.1002/ijc.27993.

26. Fattovich G, Giustina G, Schalm SW, et al. Occurrence of hepatocelIular carcinoma and decompensation in western European patients with cirrhosis type B. The EUROHEP Study Group on Hepatitis B Virus and Cirrhosis. Hepatol Balt Md. 1995;21(1):77-82.

27. Siegel AB, Zhu AX. Metabolic syndrome and hepatocellular carcinoma: two growing epidemics with a potential link. Cancer. 2009;115(24):5651-5661. http://dx.doi.org/10.1002/cncr. 24687.

28. El-Serag HB, Kramer JR, Chen GJ, Duan Z, Richardson PA, Davila JA. Effectiveness of AFP and ultrasound tests on hepatocellular carcinoma mortality in HCV-infected patients in the USA. Gut. 2011;60(7):992997. http://dx.doi.org/10.1136/gut.2010.230508.

29. White DL, Kanwal F, El-Serag HB. Association between nonalcoholic fatty liver disease and risk for hepatocellular cancer, based on systematic review. Clin Gastroenterol Hepatol Off Clin Pract J Am Gastroenterol Assoc. 2012;10(12) http://dx.doi.org/10. 1016/j.cgh.2012.10.001, 1342.e2-1359.e2.

30. Bruix J, Sherman M, Llovet JM, et al. Clinical management of hepatocellular carcinoma. Conclusions of the Barcelona-2000 EASL conference. European Association for the Study of the Liver. J Hepatol. 2001;35(3):421-430.

31. Beasley RP, Hwang LY, Lin CC, Chien CS. Hepatocellular carcinoma and hepatitis B virus. A prospective study of 22707 men in Taiwan. Lancet. 1981;2(8256):1129-1133.

32. Manno M, Cammà C, Schepis F, et al. Natural history of chronic HBV carriers in northern Italy: morbidity and mortality after 30 years. Gastroenterology. 2004;127(3):756-763.

33. Fattovich G, Brollo L, Giustina G, et al. Natural history and prognostic factors for chronic hepatitis type B. Gut. 1991;32(3):294-298.

34. Hsu Y-S, Chien R-N, Yeh C-T, et al. Long-term outcome after spontaneous $\mathrm{HBeAg}$ seroconversion in patients with chronic hepatitis B. Hepatol Balt Md. 2002;35(6):1522-1527. http://dx.doi.org/ 10.1053/jhep.2002.33638.

35. Yang H-I, Lu S-N, Liaw Y-F, et al. Hepatitis B e antigen and the risk of hepatocellular carcinoma. N Engl J Med. 2002;347(3):168-174. http://dx.doi.org/10.1056/NEJMoa013215.

36. Kumar M, Kumar R, Hissar SS, et al. Risk factors analysis for hepatocellular carcinoma in patients with and without cirrhosis: a casecontrol study of 213 hepatocellular carcinoma patients from India. J Gastroenterol Hepatol. 2007;22(7):1104-1111. http://dx.doi. org/10.1111/j.1440-1746.2007.04908.x.

37. Chen J-D, Yang H-I, lloeje UH, et al. Carriers of inactive hepatitis B virus are still at risk for hepatocellular carcinoma and liver-related death. Gastroenterology. 2010;138(5):1747-1754. http://dx. doi.org/10.1053/j.gastro.2010.01.042.

38. Yu MW, Chang HC, Liaw YF, et al. Familial risk of hepatocellular carcinoma among chronic hepatitis B carriers and their relatives. J Natl Cancer Inst. 2000;92(14):1159-1164. 
39. Chen C-J, Yang H-I, Su J, et al. Risk of hepatocellular carcinoma across a biological gradient of serum hepatitis $B$ virus DNA level. JAMA J Am Med Assoc. 2006;295(1):65-73. http://dx.doi.org/ 10.1001/jama.295.1.65.

40. Yang H-I, Sherman M, Su J, et al. Nomograms for risk of hepatocellular carcinoma in patients with chronic hepatitis B virus infection. J Clin Oncol Off J Am Soc Clin Oncol. 2010;28(14):2437-2444. http://dx.doi.org/10.1200/JC0.2009.27.4456.

41. Sun C-A, Wu D-M, Lin C-C, et al. Incidence and cofactors of hepatitis C virus-related hepatocellular carcinoma: a prospective study of 12,008 men in Taiwan. Am J Epidemiol. 2003;157(8):674-682.

42. Lok AS, Seeff LB, Morgan TR, et al. Incidence of hepatocellular carcinoma and associated risk factors in hepatitis C-related advanced liver disease. Gastroenterology. 2009;136(1):138-148. http:// dx.doi.org/10.1053/j.gastro.2008.09.014.

43. Yoshida H, Shiratori $Y$, Moriyama M, et al. Interferon therapy reduces the risk for hepatocellular carcinoma: national surveillance program of cirrhotic and noncirrhotic patients with chronic hepatitis C in Japan. IHIT Study Group. Inhibition of Hepatocarcinogenesis by Interferon Therapy. Ann Intern Med. 1999;131(3):174-181.

44. Masuzaki R, Tateishi R, Yoshida H, et al. Prospective risk assessment for hepatocellular carcinoma development in patients with chronic hepatitis $\mathrm{C}$ by transient elastography. Hepatol Balt Md. 2009;49(6):1954-1961. http://dx.doi.org/10.1002/hep.22870.

45. Sung JJY, Tsoi KKF, Wong VWS, Li KCT, Chan HLY. Meta-analysis: treatment of hepatitis $B$ infection reduces risk of hepatocellular carcinoma. Aliment Pharmacol Ther. 2008;28(9):1067-1077. http:// dx.doi.org/10.1111/j.1365-2036.2008.03816.x.

46. Liaw Y-F, Sung JJY, Chow WC, et al. Lamivudine for patients with chronic hepatitis B and advanced liver disease. N Engl J Med. 2004;351(15):1521-1531. http://dx.doi.org/10.1056/NEJMoa033364.

47. Singal AG, Volk ML, Jensen D, Di Bisceglie AM, Schoenfeld PS. A sustained viral response is associated with reduced liverrelated morbidity and mortality in patients with hepatitis $C$ virus. Clin Gastroenterol Hepatol Off Clin Pract J Am Gastroenterol Assoc. 2010;8(3) http://dx.doi.org/10.1016/j.cgh.2009.11.018, 280288, 288.e1.

48. Omata M, Lesmana LA, Tateishi R, et al. Asian Pacific Association for the Study of the Liver consensus recommendations on hepatocellular carcinoma. Hepatol Int. 2010;4(2):439-474. http://dx. doi.org/10.1007/s12072-010-9165-7.

49. Singal A, Volk ML, Waljee A, et al. Meta-analysis: surveillance with ultrasound for early-stage hepatocellular carcinoma in patients with cirrhosis. Aliment Pharmacol Ther. 2009;30(1):37-47. http://dx. doi.org/10.1111/j.1365-2036.2009.04014.x.

50. Sato T, Tateishi R, Yoshida H, et al. Ultrasound surveillance for early detection of hepatocellular carcinoma among patients with chronic hepatitis C. Hepatol Int. 2009;3(4):544-550. http://dx. doi.org/10.1007/s12072-009-9145-y.

51. Zhang B, Yang B. Combined alpha fetoprotein testing and ultrasonography as a screening test for primary liver cancer. J Med Screen. 1999;6(2):108-110.

52. Trinchet J-C, Chaffaut C, Bourcier V, et al. Ultrasonographic surveillance of hepatocellular carcinoma in cirrhosis: a randomized trial comparing 3- and 6-month periodicities. Hepatol Balt Md. 2011;54(6):1987-1997. http://dx.doi.org/10.1002/hep. 24545.

53. Han K-H, Kim DY, Park JY, et al. Survival of hepatocellular carcinoma patients may be improved in surveillance interval not more than 6 months compared with more than 6 months: a 15year prospective study. J Clin Gastroenterol. 2013;47(6):538544. http://dx.doi.org/10.1097/MCG.0b013e3182755c13.

54. Ebara M, Ohto M, Shinagawa T, et al. Natural history of minute hepatocellular carcinoma smaller than three centimeters compli- cating cirrhosis. A study in 22 patients. Gastroenterology. 1986;90(2):289-298.

55. Sheu JC, Sung JL, Chen DS, et al. Growth rate of asymptomatic hepatocellular carcinoma and its clinical implications. Gastroenterology. 1985;89(2):259-266.

56. Santi V, Trevisani F, Gramenzi A, et al. Semiannual surveillance is superior to annual surveillance for the detection of early hepatocellular carcinoma and patient survival. J Hepatol. 2010;53(2):291297. http://dx.doi.org/10.1016/j.jhep.2010.03.010.

57. Roskams T. Anatomic pathology of hepatocellular carcinoma: impact on prognosis and response to therapy. Clin Liver Dis. 2011;15(2):245-259. http://dx.doi.org/10.1016/j.cld.2011. 03.004. vii-X.

58. Di Bisceglie AM, Sterling RK, Chung RT, et al. Serum alphafetoprotein levels in patients with advanced hepatitis C: results from the HALT-C Trial. J Hepatol. 2005;43(3):434-441.

59. Tsukuma H, Hiyama T, Tanaka S, et al. Risk factors for hepatocellular carcinoma among patients with chronic liver disease. $N$ Eng/ J Med. 1993;328(25):1797-1801. http://dx.doi.org/10.1056/ NEJM199306243282501.

60. Zhou X-D, Tang Z-Y, Fan J, et al. Intrahepatic cholangiocarcinoma: report of 272 patients compared with 5,829 patients with hepatocellular carcinoma. J Cancer Res Clin Oncol. 2009;135(8):10731080. http://dx.doi.org/10.1007/s00432-009-0547-y.

61. Trevisani F, D'Intino PE, Morselli-Labate AM, et al. Serum alphafetoprotein for diagnosis of hepatocellular carcinoma in patients with chronic liver disease: influence of HBsAg and anti-HCV status. J Hepatol. 2001;34(4):570-575.

62. Sherman M, Peltekian KM, Lee C. Screening for hepatocellular carcinoma in chronic carriers of hepatitis B virus: incidence and prevalence of hepatocellular carcinoma in a North American urban population. Hepatol Balt Md. 1995;22(2):432-438.

63. McMahon BJ, Bulkow L, Harpster A, et al. Screening for hepatocellular carcinoma in Alaska natives infected with chronic hepatitis B: a 16-year population-based study. Hepatol Balt Md. 2000;32(4 Pt 1):842-846. http://dx.doi.org/10.1053/jhep.2000.17914.

64. Lok AS, Sterling RK, Everhart JE, et al. Des-gamma-carboxy prothrombin and alpha-fetoprotein as biomarkers for the early detection of hepatocellular carcinoma. Gastroenterology. 2010;138(2):493-502. http://dx.doi.org/10.1053/j.gastro.2009.10.031.

65. Zapka JG, Taplin SH, Solberg LI, Manos MM. A framework for improving the quality of cancer care: the case of breast and cervical cancer screening. Cancer Epidemiol Biomark Prev Publ Am Assoc Cancer Res Cosponsored Am Soc Prev Oncol. 2003;12(1):4-13.

66. Singal AG, Nehra M, Adams-Huet B, et al. Detection of hepatocellular carcinoma at advanced stages among patients in the HALT-C trial: where did surveillance fail? Am J Gastroenterol. 2013;108(3):425432. http://dx.doi.org/10.1038/ajg.2012.449.

67. Davila JA, Henderson L, Kramer JR, et al. Utilization of surveillance for hepatocellular carcinoma among hepatitis $C$ virus-infected veterans in the United States. Ann Intern Med. 2011;154(2):85-93. http:// dx.doi.org/10.7326/0003-4819-154-2-201101180-00006.

68. Park SH, Heo NY, Park JH, et al. Hepatocellular carcinoma screening in a hepatitis B virus-infected Korean population. Dig Dis Sci. 2012;57(12):3258-3264. http://dx.doi.org/10.1007/ s10620-012-2281-6.

69. Aberra FB, Essenmacher M, Fisher N, Volk ML. Quality improvement measures lead to higher surveillance rates for hepatocellular carcinoma in patients with cirrhosis. Dig Dis Sci. 2013;58(4):11571160. http://dx.doi.org/10.1007/s10620-012-2461-4.

70. Paul SB, Sreenivas V, Gulati MS, et al. Economic evaluation of a surveillance program of hepatocellular carcinoma (HCC) in India. Hepatol Int. 2008;2(2):231-236. http://dx.doi.org/10.1007/ s12072-008-9054-5. 